\title{
Avaliação da adição de dolomita em massa de cerâmica de revestimento de queima vermelha
}

\section{Evaluation of the addition of dolomite to red ceramic mass for the production of glazed ceramics}

\author{
R.A.L.Soares ${ }^{1,2, *}$, R.M.do Nascimento ${ }^{2}$, C.A.Paskocimas ${ }^{2}$, R. J.S. Castro ${ }^{2,3}$ \\ ${ }^{1}$ Instituto Federal de Educação, Ciência e Tecnologia do Piauí - IFPI \\ ${ }^{2}$ Programa de Pós-Graduação em Ciência e Engenharia de Materiais, \\ Universidade Federal do Rio Grande do Norte - UFRN \\ ${ }^{3}$ Universidade Federal do Piauí - UFPI \\ *robertoarruda@ifpi.edu.br
}

\begin{abstract}
Resumo
A dolomita é um mineral encontrado em abundância no estado do Piauí, ao mesmo tempo é desconsiderada pela indústria cerâmica. A sua formação química-mineralógica aponta para uma potencialidade de aplicação em massa cerâmica de revestimento, devido à presença de óxidos fundentes e outros capazes de formar novas fases cristalinas que contribuem na melhoria da estabilidade dimensional e resistência mecânica dos corpos cerâmicos. Desta forma, o presente trabalho tem como objetivo avaliar a potencialidade do uso de um carbonato dolomítico na produção de cerâmica de revestimento de base vermelha. Para isso foram caracterizadas uma massa cerâmica usada na produção de revestimento semiporoso e dolomita oriunda de uma jazida piauiense. $\mathrm{O}$ carbonato foi adicionado à massa industrial em diferentes teores e as formulações foram queimadas em três temperaturas: $1080{ }^{\circ} \mathrm{C}, 1120{ }^{\circ} \mathrm{C}$ e $1160{ }^{\circ} \mathrm{C}$. Foram realizados nos corpos de prova queimados ensaios tecnológicos de retração linear, absorção de água, massa específica aparente e resistência mecânica. A microestrutura foi avaliada através de análise por difração de raios X e microscopia eletrônica de varredura. Os resultados mostraram potencialidade da aplicação da dolomita piauiense em massa de revestimento cerâmico.

Palavras-chave: dolomita, massa industrial, cerâmica de revestimento, propriedades tecnológicas.
\end{abstract}

\begin{abstract}
Although dolomite is abundant in the Brazilian northern state of Piaui, it has not been used by the local ceramic industry. As a result of its chemical and mineralogical characteristics, dolomite can be used in the fabrication of glazed ceramics. Among the potential benefits, the presence of flux oxides and other constituents may improve dimensional stability and mechanical strength of the ceramic. This study aimed at evaluating the addition of dolomitic carbonate to red ceramic mass for the production of glazed ceramics. To that end, different contents of carbonate were added to an industrial ceramic mass traditionally used in the local production of semiporous glazed ceramics. Samples were fired at three temperatures: $1080^{\circ} \mathrm{C}, 1120^{\circ} \mathrm{C}$, and $1160^{\circ} \mathrm{C}$. Linear shrinkage, water absorption, apparent specific gravity, mechanical strength and microstructural evaluation were all carried out. The results showed the potential application of Piaui dolomite in ceramic tile. Keywords: dolomite, ceramic mass, glazed red ceramics.
\end{abstract}

\section{INTRODUÇÃO}

O estado do Piaui, nordeste do Brasil, com uma extensão territorial de $251.529 .186 \mathrm{~km}^{2}$, possui uma grande quantidade de jazidas de argilas, sendo que $11,8 \%$ dos seus solos são argilosos [1], o que o torna um estado atrativo para produção de artefatos cerâmicos. As indústrias cerâmicas da região produzem cerâmica de revestimento e cerâmica estrutural de queima vermelha, principalmente telhas e tijolos. Também possui jazidas de quartzo, talco e carbonatos calcítico e dolomítico que poderiam ser utilizados na produção de cerâmica de revestimento [2].

Os carbonatos de cálcio e/ou magnésio são amplamente aplicados na indústria de revestimento com finalidades diversas, pois atua como fundente energético, promove a porosidade requerida e aumenta a resistência dos corpos cerâmicos, mas principalmente para melhorar estabilidade dimensional da peça [3]. Os carbonatos são principalmente introduzidos na massa cerâmica de revestimento de alta porosidade, mas podem também compor a massa cerâmica de revestimento de baixa porosidade. A quantidade a ser adicionada na massa e a temperatura de queima dependem das características que se deseja do produto final. Porém a sua utilização na massa cerâmica requer cuidados principalmente no que se refere a granulometria e ao ciclo de queima adotado, para se evitar o surgimento de defeitos nas peças, principalmente na etapa de queima [4]. O carbonato mais utilizado para tais fins é a calcita e as aplicações dos carbonatos são realizadas normalmente em cerâmica de queima branca [5]. Atualmente, o carbonato dolomítico 
piauiense é utilizado apenas em aplicação agrícola na correção da acidez do solo. Este carbonato tem uma característica peculiar, pois além da presença dos álcalis terrosos, $\mathrm{CaO}$ e $\mathrm{MgO}$, apresenta a presença do mineral fundente ortoclásio, fonte do álcali potássio. Os fundentes são bastante utilizados pela indústria cerâmica, pois são essenciais no processo de sinterização das formulações cerâmicas durante a queima. Assim, o presente trabalho tem como objetivo avaliar a potencialidade da aplicação de uma dolomita proveniente do estado do Piauí em massa de cerâmica de revestimento de queima vermelha do tipo semiporoso cuja composição é desprovida de carbonatos e assim, proporcionar uma utilização mais adequada e agregar valor a esta matéria-prima até então desconsiderada pelo setor cerâmico.

\section{MATERIAIS E MÉTODOS}

No presente trabalho, utilizou-se como base a formulação cerâmica empregada na produção de revestimento cerâmico do tipo semiporoso. Decidiu-se utilizar a massa da forma como coletada, sem beneficiamento adicional. A dolomita foi fornecida por uma mineradora que explora uma jazida localizada no município de José Freitas a $50 \mathrm{~km}$ de Teresina. Visando permitir a sua utilização na massa padrão, a dolomita passou por uma etapa de moagem realizada em moinho excêntrico por $2 \mathrm{~h}$ para passar em uma peneira de 200 mesh.

A composição química das matérias-primas foi determinada por fluorescência de raios $\mathrm{X}$, em equipamento Shimadzu EDX-700. Os resultados são apresentados na forma dos óxidos mais estáveis dos elementos químicos presentes. A análise mineralógica das matérias-primas, bem como as fases formadas após a queima dos corpos de prova foi obtida por difração de raios X Shimadzu XRD-6000 com tubo de $\mathrm{Cu}(\lambda=1,54056 \AA)$, tensão $40 \mathrm{kV}$ e corrente 30 $\mathrm{mA}$, com varredura de $5^{\circ}$ a $80^{\circ}$ para $2 \theta$, com velocidade $2^{\circ} \%$ min e $0,02 \%$ passo. Com base nos resultados de fluorescência de raios $\mathrm{X}$ e difração de raios $\mathrm{X}$, foi realizada a análise racional da massa industrial e do carbonato dolomítico, utilizando-se o programa computacional para análise racional de argilominerais "MIDS" desenvolvido na UFRN [6]. Para avaliação térmica das matérias-primas, utilizouse o analizador termogravimétrico TGA-51H Shimadzu e o analisador termodiferencial DTA-50H Shimadzu. Para os dois tipos de análise, foram utilizadas massas de $\sim 15$ $\mathrm{mg}$, com granulometria inferior a 200 mesh, sob um fluxo de ar sintético de $50 \mathrm{~mL} / \mathrm{min}$. A taxa de aquecimento foi de $10{ }^{\circ} \mathrm{C} /$ min entre $27{ }^{\circ} \mathrm{C}$ e $1200{ }^{\circ} \mathrm{C}$. A análise dos resultados e a obtenção da curva derivada da TG, foram realizadas com o programa de computador TA-60 Shimadzu. A perda ao fogo das matérias-primas foi obtida pela medida de perda de massa entre $110{ }^{\circ} \mathrm{C}$ e $1200{ }^{\circ} \mathrm{C}$ durante o ensaio de termogravimetria. Além disso, foi feita a análise dilatométrica na massa industrial. A dilatometria foi em dilatômetro BP Engenharia RB-115, com capacidade para atingir $1650{ }^{\circ} \mathrm{C}$; este possui como ferramenta adicional o software para análise dilatométrica RB-3000. Foi usada uma taxa de aquecimento de $10^{\circ} \mathrm{C} / \mathrm{min}$ até $1100^{\circ} \mathrm{C}$.

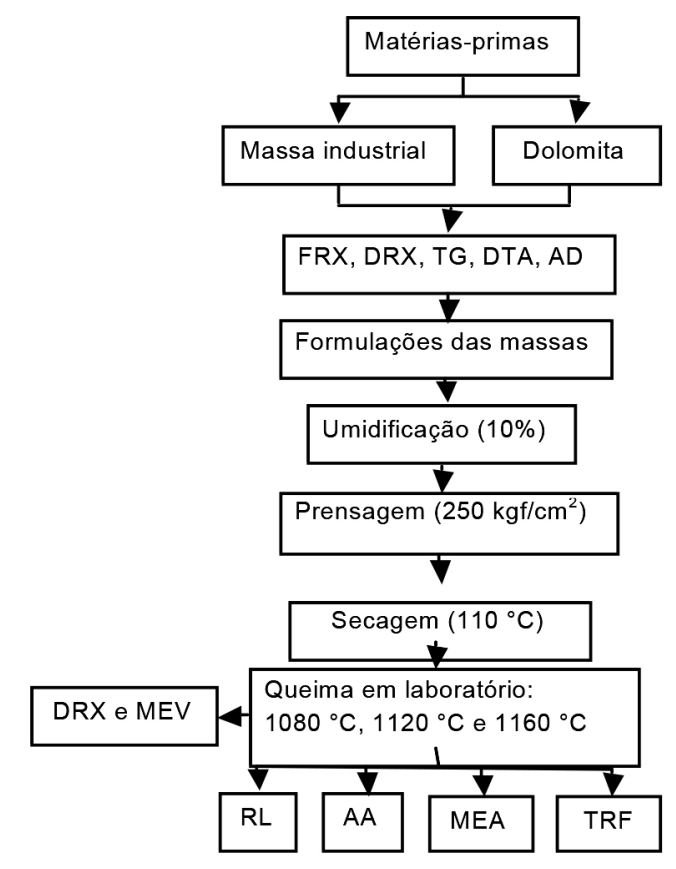

Figura 1: Fluxograma do procedimento experimental. [Figure 1: Flowchart of the experimental procedure.]

Após a secagem das matérias-primas, as composições das massas foram obtidas com adição da dolomita nos teores de $0,2,4,8$ e $16 \%$ na massa industrial, conforme mostra a Tabela I:

As condições de processamento e queima foram fixadas, variando apenas a quantidade de carbonatos adicionados à massa industrial. Os percentuais de 2, 4, 8 e $16 \%$ em peso adicionados de massa dos carbonatos foram utilizados segundo um modelo exponencial, pois tal adição propicia um melhor acompanhamento das transformações ocorridas durante a queima e com a variação da temperatura [7]; também proporciona avaliar o comportamento das formulações em baixas e altas concentrações de carbonatos com um menor número de formulações. Visando permitir o processamento da massa, adicionou-se água em 10\% do peso total da massa. Em seguida foram homogeneizadas, granuladas em peneira malha 40 mesh e vedadas em sacos plásticos por $24 \mathrm{~h}$ para melhor distribuição da água entre as

Tabela I - Composições das massas.

[Table I - Ceramic mass compositions.]

\begin{tabular}{ccc}
\hline \multirow{2}{*}{$\begin{array}{c}\text { Composição } \\
\text { das massas }\end{array}$} & \multicolumn{2}{c}{ Concentração em peso (\%) } \\
Massa industrial & Dolomita \\
\hline MI & 100 & 0 \\
D2 & 98 & 2 \\
D4 & 96 & 4 \\
D8 & 92 & 8 \\
D16 & 84 & 16 \\
\hline
\end{tabular}


partículas da massa cerâmica. A conformação dos corpos de prova foi feita por prensagem uniaxial sob $25 \mathrm{MPa}$, obtendo peças na forma de paralelepípedo nas dimensões $60 \mathrm{~mm} \times 20 \mathrm{~mm} \times 5 \mathrm{~mm}$ e pesando $15 \mathrm{~g}$ cada. Após a etapa de conformação, os corpos de prova foram secos em estufa a $110{ }^{\circ} \mathrm{C}$ por $24 \mathrm{~h}$. A etapa de queima dos corpos de prova foi em forno de laboratório a $1080{ }^{\circ} \mathrm{C}, 1120{ }^{\circ} \mathrm{C}$ e $1160{ }^{\circ} \mathrm{C}$, com taxa de aquecimento $10^{\circ} \mathrm{C} / \mathrm{min}$ em cada queima e patamar de $10 \mathrm{~min}$. O resfriamento ocorreu de forma natural, com as amostras dentro do forno desligado, até alcançar a temperatura ambiente.

Os corpos de prova queimados foram avaliados em suas propriedades tecnológicas de retração linear (RL), absorção de água (AA), massa específica aparente (MEA) e tensão de ruptura à flexão em três pontos (TRF). A análise microestrutural foi feita por meio da avaliação por DRX das fases cristalinas presentes nas peças após a queima e a topografia da superfície fraturada sem ataque químico por microscopia eletrônica de varredura (MEV).

\section{RESULTADOS E DISCUSSÃO}

A massa industrial é constituída majoritariamente pelos óxidos de silício e de alumínio e de natureza não carbonácea devido ao baixo teor de $\mathrm{CaO}$, conforme apresenta a Tabela II. Estes óxidos estão associados principalmente ao argilomineral ilita $\left[\left(\mathrm{KH}_{3} \mathrm{O}\right) \mathrm{Al}_{2} \mathrm{Si}_{3} \mathrm{Al}_{10}(\mathrm{OH})_{2}\right]$, de acordo os resultados da análise mineralógica apresentados na Fig. 2. $\mathrm{O}$ teor de $6,6 \%$ de potássio mostra que a massa industrial é composta por argilas fundentes para auxiliar na formação de fase líquida reduzindo a temperatura de sinterização. A presença do quartzo $\left(\mathrm{SiO}_{2}\right)$ indica que parte do silício está também associado a este mineral. $\mathrm{O} \mathrm{SiO}_{2}$ presente no argilomineral combinado aos outros componentes como $\mathrm{Al}_{2} \mathrm{O}_{3}$ e os fundentes, formam durante a queima fase vítrea e novas fases cristalinas, enquanto o quartzo não dissolvido, desempenha um importante papel na estabilidade estrutural da peça cerâmica.

$\mathrm{O}$ alto teor de ferro $(10,4 \%)$ confirma a coloração vermelha da peça cerâmica após a queima e está associado à presença da hematita $\left(\mathrm{Fe}_{2} \mathrm{O}_{3}\right)$ detectada na análise mineralógica. $\mathrm{O}$ carbonato dolomítico $\left(\mathrm{CaMg}\left(\mathrm{CO}_{3}\right)_{2}\right)$ é composto principalmente por $\mathrm{CaO}$ e $\mathrm{MgO}$, mas também apresenta outros óxidos que justificam a presença do quartzo e ortoclásio $\left[\mathrm{K}(\mathrm{Al}, \mathrm{Fe}) \mathrm{Si}_{2} \mathrm{O}_{8}\right]$ em sua composição mineralógica apresentada na Fig. 3. O teor de ferro da dolomita $(5,3 \%)$ está ligado ao ortoclásio e a algum mineral amorfo presente. Os elementos alcalinos terrosos $(\mathrm{CaO}$ e $\mathrm{MgO}$ ) presentes nos carbonatos atuam como fundentes moderados ou muito energéticos, dependendo da quantidade e temperatura de queima da massa cerâmica.

O resultado da análise termogravimétrica da dolomita é apresentado na Fig. 4. A perda de massa foi de 39,26\%. Esta

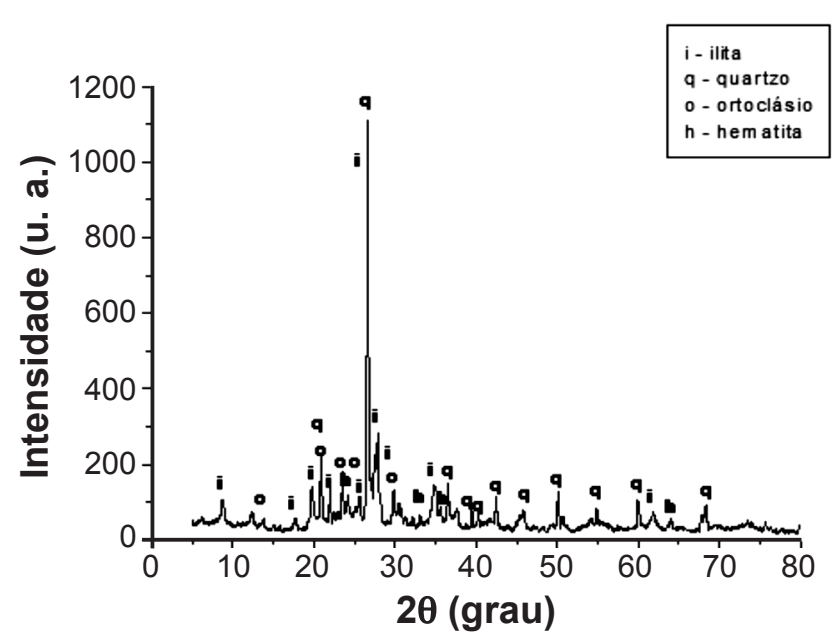

Figura 2: Difratograma de raios $X$ da massa industrial. [Figure 2: X-ray diffraction pattern of the industrial mass.]

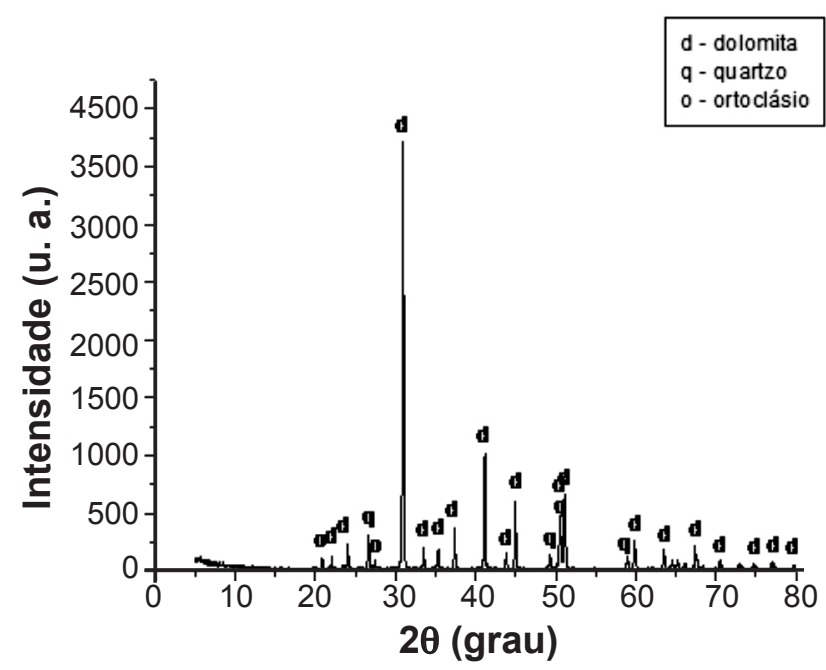

Figura 3: Difratograma de raios $\mathrm{X}$ da dolomita.

[Figure 3: X-ray diffraction pattern of the dolomitic carbonate.]

Tabela II - Componentes químicos das matérias-primas.

[Table II - Chemical composition of the raw materials (\% equivalent oxide).]

\begin{tabular}{ccccccccc}
\hline & \multicolumn{7}{c}{ Óxidos (\% em peso ) } \\
\cline { 2 - 8 } Matéria-prima & $\mathrm{SiO}_{2}$ & $\mathrm{Al}_{2} \mathrm{O}_{3}$ & $\mathrm{Fe}_{2} \mathrm{O}_{3}$ & $\mathrm{~K}_{2} \mathrm{O}$ & $\mathrm{CaO}$ & $\mathrm{MgO}$ & $\mathrm{TiO}_{2}$ & outros \\
\hline \multirow{2}{*}{ Massa industrial } & 51,9 & 25,5 & 10,4 & 6,6 & 0,4 & 2,0 & 0,9 & 2,3 \\
Dolomita & 12,7 & 4,3 & 5,2 & 1,5 & 52,5 & 20,8 & 0,2 & 2,8 \\
\hline
\end{tabular}


Tabela III - Concentração das fases cristalinas das matérias-primas.

[Table III - Concentration of crystalline phases in the raw materials.]

\begin{tabular}{cccccc}
\hline \multicolumn{7}{c}{ Fases identificadas (\%) } \\
\hline Matéria-prima & ilita & quartzo & hematita & ortoclásio & dolomita \\
Massa industrial & 69,8 & 15,7 & 10,4 & 1,7 & - \\
Dolomita & - & 3,9 & - & 13,6 & 82,5 \\
\hline
\end{tabular}

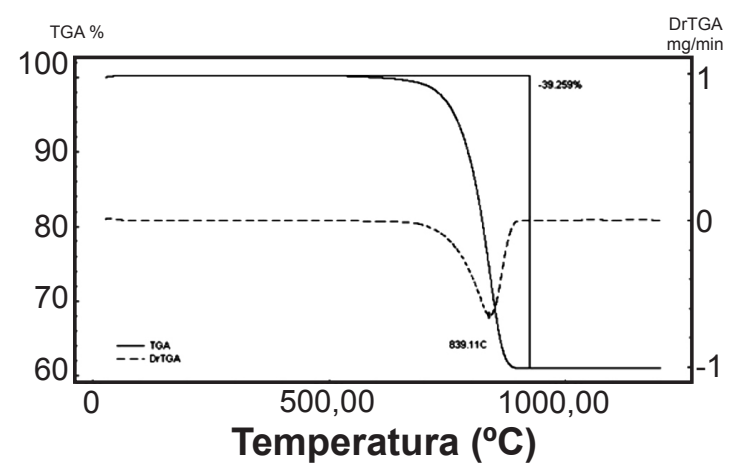

Figura 4: Curva termogravimétrica (TG) com derivada (DTG) da dolomita.

[Figure 4: Thermogravimetric curve of dolomite and corresponding derivative.]

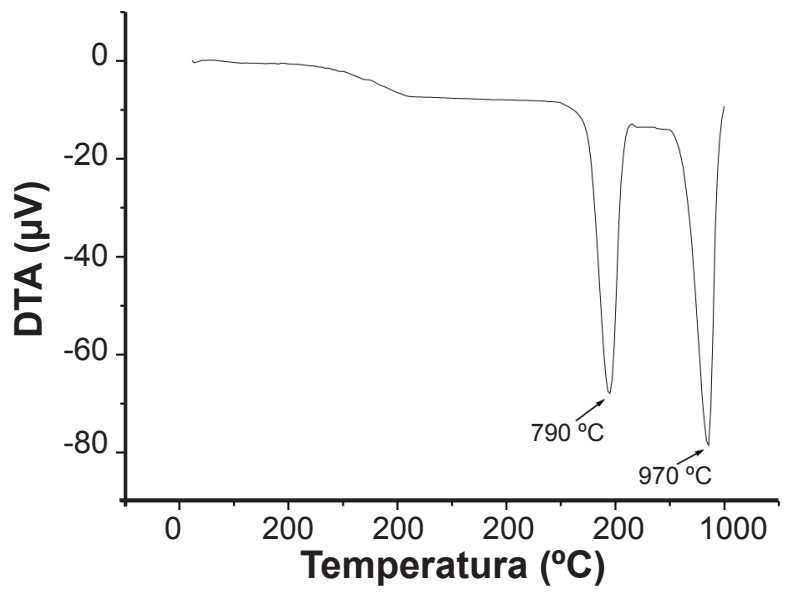

Figura 5: Curva termodiferencial (DTA) da dolomita.

[Figure 5: Curves of differential thermal analysis of dolomite.]

perda significativa de massa está relacionada principalmente com a saída do $\mathrm{CO}_{2}$ decorrente da decomposição do mineral dolomita durante a queima entre $750{ }^{\circ} \mathrm{C}$ e $980{ }^{\circ} \mathrm{C}$, onde se verifica uma inclinação acentuada da curva TG. Esta ocorrência pode ser confirmada na Fig. 5, que apresenta o resultado da análise térmica diferencial:

A curva DTA da dolomita apresenta dois picos significativos, um em $790{ }^{\circ} \mathrm{C}$ e outro a $970{ }^{\circ} \mathrm{C}$. O primeiro está relacionado à saída do $\mathrm{CO}_{2}$ ligado ao $\mathrm{MgO}$, e o segundo à eliminação do $\mathrm{CO}_{2}$ ligado ao $\mathrm{CaO}$.

A curva termogravimétrica (Fig. 6) mostra perda de massa de $2,56 \%$ até em torno de $230{ }^{\circ} \mathrm{C}$ correspondente à saída da água livre e eliminação da água adsorvida. Estes fenômenos podem ser corroborados pelos picos endotérmicos em $30{ }^{\circ} \mathrm{C}$ e $120{ }^{\circ} \mathrm{C}$ (maior intensidade) verificados na curva termodiferencial da massa industrial (Fig. 7). Depois, $230{ }^{\circ} \mathrm{C}$ até $1200{ }^{\circ} \mathrm{C}$, houve uma perda de massa de $\sim 4 \%$. Esta perda pode estar relacionada com a carbonização da matéria orgânica, entre $300{ }^{\circ} \mathrm{C}$ e $350{ }^{\circ} \mathrm{C}$, e a eliminação da água de constituição dos argilominerais, que é responsável pela maior perda de massa nesta faixa de temperatura. Também na curva DTA são observados mais três picos endotérmicos de baixa intensidade, o primeiro $\left(485^{\circ} \mathrm{C}\right)$ corresponde à perda de água de hidroxilas dos componentes argilominerais da massa industrial, mas que não destrói a estrutura cristalina das ilíticas; o segundo pico endotérmico $\left(573{ }^{\circ} \mathrm{C}\right)$ é devido a transformação alotrópica do quartzo $\alpha$ em $\beta$ [8]; o terceiro $\left(885^{\circ} \mathrm{C}\right)$ está

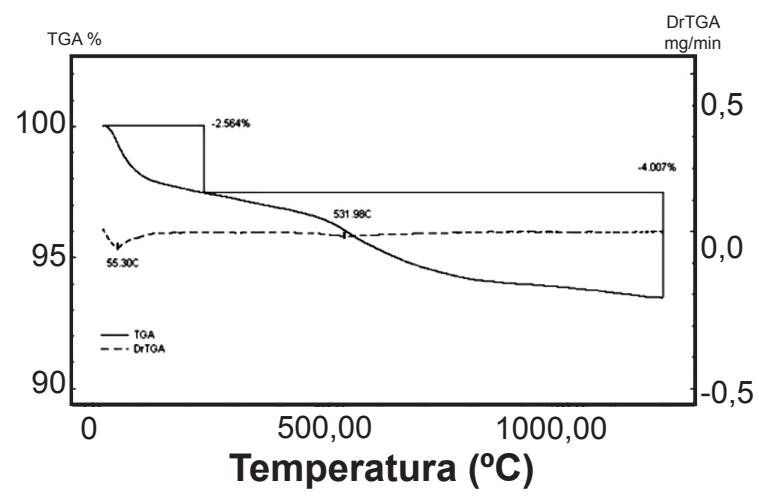

Figura 6: Curva termogravimétrica (TG) com derivada (DTG) da massa industrial.

[Figure 6: Thermogravimetric curve of industrial mass and corresponding derivative.]

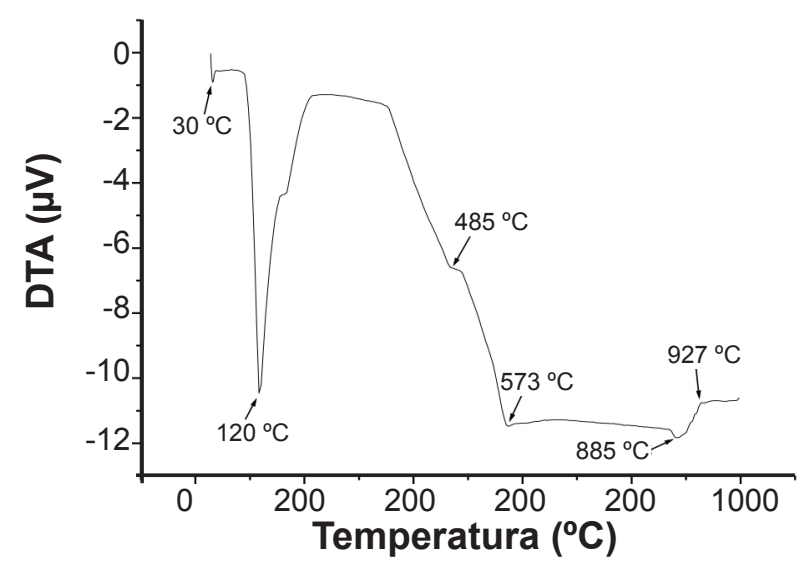

Figura 7: Curva termodiferencial (DTA) da massa industrial. [Figure 7: Thermodifferential curve of the industrial mass.] 
relacionado à perda da estrutura cristalina das argilas ilíticas que compõem a massa industrial. A $927^{\circ} \mathrm{C}$ há um pico exotérmico de baixa intensidade, que pode estar relacionado com a formação de espinélio.

Observa-se na curva dilatométrica apresentada na Fig. 8 que entre $100{ }^{\circ} \mathrm{C}$ e $200{ }^{\circ} \mathrm{C}$, a MI teve uma pequena retração, ocorrida da eliminação da água de conformação. Com a saída da água, surgem vazios, assim ocorre uma aproximação das partículas e, em consequência, das forças de atração eletrostáticas provocando o adensamento [9]. De $200^{\circ} \mathrm{C}$ a $600{ }^{\circ} \mathrm{C}$, a curva dilatométrica tem comportamento de expansão linear. Este comportamento é causado pelo aumento na amplitude vibracional entre seus átomos à medida que se aumenta a temperatura. Vale ressaltar que nesta faixa de temperatur, pode ocorrer retração do corpo cerâmico em consequência da carbonização da matéria orgânica e a desidroxilação do argilomineral, porém a expansão se sobrepôs à retração. Entre $600{ }^{\circ} \mathrm{C}$ e $640{ }^{\circ} \mathrm{C}$, a curva dilatométrica tem uma inclinação ascendente mais acentuada. Este comportamento está relacionado com a transformação polimórfica do quartzo que provoca um aumento de volume. A expansão do corpo cerâmico continua até cerca de $870{ }^{\circ} \mathrm{C}$ (temperatura de expansão máxima). Em seguida ocorre uma abrupta retração provocada pelo início da sinterização com a formação de fase líquida e densificação. A inclinação descendente bem acentuada da curva dilatométrica mostra que há uma formação de grande quantidade fase líquida, a partir de $870{ }^{\circ} \mathrm{C}$, promovida pelos óxidos fundentes presente na MI. O silício proveniente da decomposição dos argilominerais reage com estes óxidos formando fase líquida que escoa para os interstícios entre as partículas mais refratárias, e por ação de capilaridade, promove a aproximação das partículas do corpo cerâmico.

A Tabela IV apresenta os resultados das fases cristalinas detectadas pela análise por difração de raios $\mathrm{X}$ nas formulações MI, D4 e D16 após a queima nas três temperaturas avaliadas:

Como pode ser observado, o quartzo e a hematita são as fases que estão presentes em todas as formulações e temperaturas estudadas, sendo o quartzo a fase predominante devido seu alto ponto de fusão. Durante a queima o quartzo se dissolve apenas parcialmente e mantém a estrutura do corpo cerâmico. Também foi observado que à medida que aumenta a temperatura, ocorre uma maior dissolução do quartzo na fase líquida formada (fase amorfa); este quartzo dissolvido reage com os demais constituintes da massa contribuindo na formação de novas fases. Com o aumento da temperatura, os silicatos presentes na massa vão perdendo viscosidade, e desta forma, aumenta sua capacidade de diluir as partículas com as quais estão em contato [10]. A hematita também é reduzida parcialmente com o aumento da temperatura, ou seja, em temperatura mais elevada ocorre a liberação de $\mathrm{O}_{2}$ da hematita na fase líquida formada, que favorece a redução da retração de queima devido ao aprisionamento deste gás no interior das peças cerâmicas [11]. Isto é confirmado com os resultados de retração linear e massa específica aparente, como poderá ser observado posteriormente.

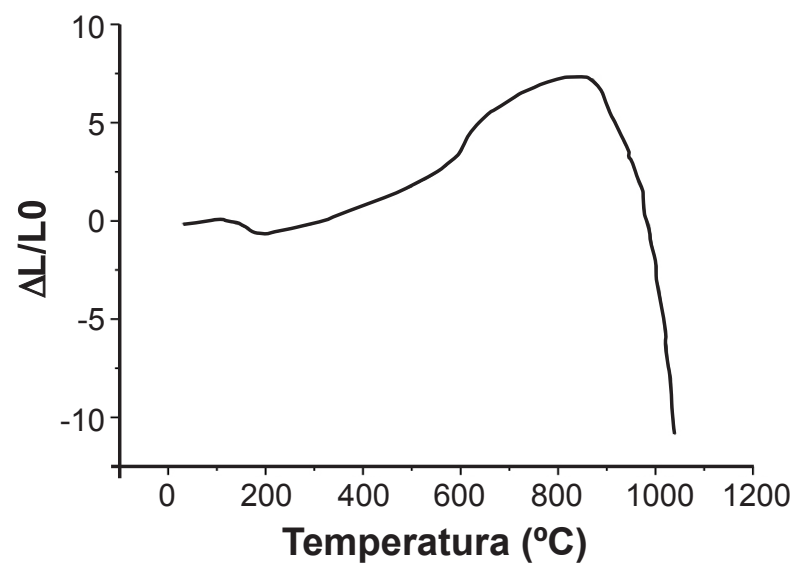

Figura 8: Curva dilatométrica da massa industrial.

[Figure 8: Dilatometric curve of the industrial mass.]

Tabela IV - fases cristalinas detectadas nas amostras MI, D4 e D16 nas três temperaturas de queima.

[Table IV - Crystalline phases in samples IM, D4 and D16 after firing.]

\begin{tabular}{cccc}
\hline \multirow{2}{*}{ TEMPERATURA } & \multicolumn{3}{c}{ FORMULAÇÕES } \\
& MI & D4 & D16 \\
\hline $1080{ }^{\circ} \mathrm{C}$ & $\mathrm{q}, \mathrm{h}$ & $\mathrm{q}, \mathrm{h}, \mathrm{d}$ & $\mathrm{q}, \mathrm{h}, \mathrm{a}, \mathrm{g}$ \\
$1120^{\circ} \mathrm{C}$ & $\mathrm{q}, \mathrm{h}, \mathrm{e}$ & $\mathrm{q}, \mathrm{h}, \mathrm{e}, \mathrm{d}$ & $\mathrm{q}, \mathrm{h}, \mathrm{a}, \mathrm{g}$ \\
$1160^{\circ} \mathrm{C}$ & $\mathrm{q}, \mathrm{h}, \mathrm{e}$ & $\mathrm{q}, \mathrm{h}, \mathrm{e}, \mathrm{a}$ & $\mathrm{q}, \mathrm{h}, \mathrm{a}, \mathrm{d}$ \\
\hline
\end{tabular}

*q: quartzo - h: hematita - e: espinélio - d: diopsita - a: anortita g; guelenita

A fase ilita não foi identificada devido à perda de sua estrutura cristalina em $885{ }^{\circ} \mathrm{C}$, observada na curva termodiferencial da MI. A saída das moléculas de água da estrutura cristalina da ilita destrói o seu arranjo cristalino característico, formando uma nova fase amorfa. O espinélio $\left(\mathrm{Al}_{2} \mathrm{MgO}_{4}\right.$ ) foi identificado a partir de $1120^{\circ} \mathrm{C}$ nas formulações MI e D4. O espinélio é uma fase cristalina formada a partir da fase amorfa proveniente dos argilominerais e promove o aumento da resistência mecânica das peças cerâmicas. Além disso, a fusão do ortoclásio contribui para a formação de fase vítrea, também responsável pelo aumento da TRF dos corpos cerâmicos.

Como se pode observar nas composições com carbonatos, foram identificadas fases cristalinas à base de cálcio e magnésio como a anortita $\left(\mathrm{CaAl}_{2} \mathrm{Si}_{2} \mathrm{O}_{8}\right)$, diopsita $\left[\mathrm{Ca}(\mathrm{Mg}, \mathrm{Al})(\mathrm{Si}, \mathrm{Al})_{2} \mathrm{O}_{8}\right]$ e guelenita $\left[\mathrm{Ca}_{2} \mathrm{Al}(\mathrm{Al}, \mathrm{Si})_{2} \mathrm{O}_{7}\right]$. Com a decomposição dos carbonatos, $\mathrm{CaO}$ e $\mathrm{MgO}$ livres reagem com a sílica e alumina provenientes da fase amorfa formada a partir da decomposição dos argilominerais, formando estes silicatos e aluminossilicatos de cálcio e magnésio. Estas fases é que determinam diferenças nas propriedades tecnológicas dos materiais com carbonatos comparados aos de massa sem carbonato. $\mathrm{O}$ ferro presente na massa industrial também tende a combinar com os óxidos de cálcio e de magnésio formando silicatos duplos, porém não foram identificados picos referentes a estes tipos de fase cristalina.

O resultado da retração linear de queima apresentado na 
Fig. 9 mostra que os corpos de prova da $\mathrm{MI}$ queimados a $1080{ }^{\circ} \mathrm{C}$ e a $1160{ }^{\circ} \mathrm{C}$ retraíram menos que os queimados a $1120{ }^{\circ} \mathrm{C}$. Com o aumento da temperatura de $1080{ }^{\circ} \mathrm{C}$ a $1120{ }^{\circ} \mathrm{C}$, o processo de sinterização se torna mais efetivo com a formação de fase líquida e densificação da massa cerâmica promovida pelos óxidos fundentes presente na MI. O silício proveniente da decomposição dos argilominerais reage com estes óxidos formando fase líquida que escoa para os interstícios entre as partículas mais refratárias, e por ação de capilaridade, promove a aproximação das partículas do corpo cerâmico e diminui a porosidade. A $1160{ }^{\circ} \mathrm{C}$ ocorreu uma retração de menor magnitude comparada a queima a $1120{ }^{\circ} \mathrm{C}$. Isto pode ter ocorrido devido ao fechamento dos poros na superfície dos corpos cerâmicos que impedem a saída do oxigênio proveniente da decomposição da hematita. Esta hipótese pode ser confirmada posteriormente com a análise microestrutural.

O efeito da adição de dolomita na formulação cerâmica é observado por uma menor retração linear de queima. Isto mostra a adição de dolomita na massa de referência possibilitou uma melhor estabilidade dimensional. É de grande interesse industrial a utilização de uma massa cerâmica que possibilite a uniformidade de seus produtos, assim a dolomita estudada aponta como uma alternativa que possibilite este efeito. A estabilidade dimensional promovida pela dolomita está ligada aos álcalis terrosos. Estes reagem com os demais componentes da massa formando silicatos e aluminossilicatos de cálcio que sofrem expansão por apresentarem densidades menores que as fases originais. Além disso, estas fases a base de cálcio interferem na formação na formação de fase líquida, principal responsável pela densificação e consequente retração da peça cerâmica.

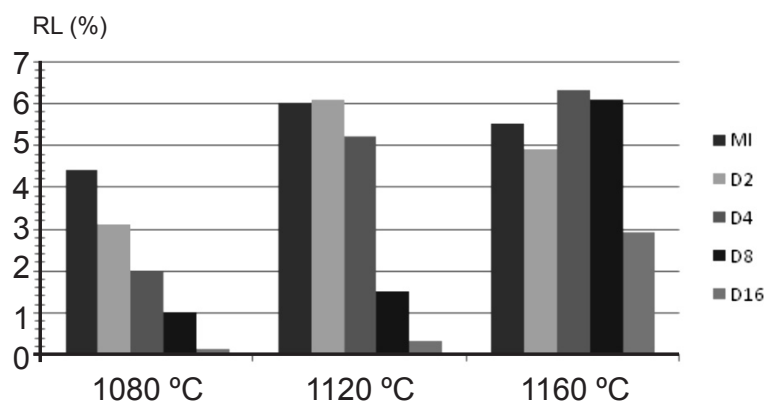

Figura 9: Retração linear de queima nas temperaturas estudadas. [Figure 9: Linear firing shrinkage at the temperatures studied.]

Isto fica evidenciado com os resultados da absorção de água (Fig. 10) e da massa específica aparente (Fig. 11). Pode-se observar o aumento da AA e a diminuição da MEA à medida que aumenta a participação da dolomita na massa. $\mathrm{O}$ aumento da porosidade à medida que se aumenta a quantidade de dolomita na massa se deve também a maior quantidade de $\mathrm{CO}_{2}$ que sai das amostras com a decomposição da dolomita durante a queima. Entre $1140{ }^{\circ} \mathrm{C}$ e $1160{ }^{\circ} \mathrm{C}$ as formulações tiveram uma redução acentuada da AA, principalmente as composições com maior teor de dolomita. Isto mostra que os óxidos de cálcio e magnésio oriundos da decomposição dos carbonatos têm ação fundente muito forte em temperatura mais elevada, formando fase líquida de baixa viscosidade [12] que preenchem os espaços vazios entre as partículas mais refratárias da peça, promovendo uma menor porosidade e maior densificação da peça cerâmica.

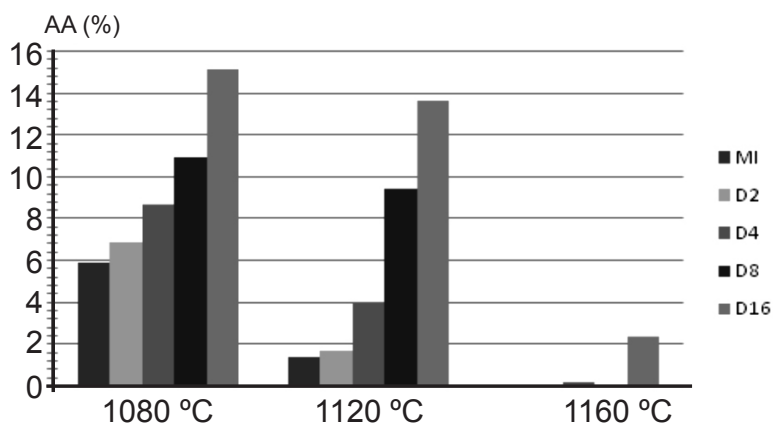

Figura 10: Absorção de água nas temperaturas estudadas. [Figure 10: Water absorption as a function of dolomite content and firing temperature.]

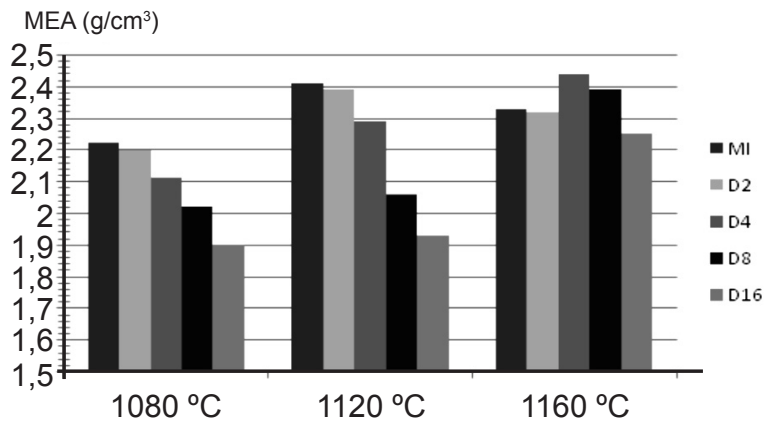

Figura 11: massa específica aparente nas temperaturas estudadas. [Figure 11: Apparent specific gravity as a function of dolomite content and firing temperature.]

De acordo com a Fig. 12, todas as formulações tiveram um aumento da resistência mecânica com o aumento da temperatura, porém as composições com dolomita tiveram um aumento mais significativo da TRF que a MI com o aumento da temperatura. $\mathrm{O}$ aumento da resistência com o aumento da temperatura ocorre devido à redução da porosidade e a microestrutura formada no processo de sinterização, como a fase vítrea e as novas fases cristalinas que proporcionam maior resistência ao corpo cerâmico. Também se observa que a formulação D2 atingiu resistência mecânica superior a MI a partir de $1120{ }^{\circ} \mathrm{C}$ e as demais formulações em $1160{ }^{\circ} \mathrm{C}$. Também se observa que o aumento da TRF com o aumento da temperatura das composições com carbonatos foi mais discreto com as formulações com menor teor e, mais expressivo com as de maior teor, principalmente entre $1140{ }^{\circ} \mathrm{C}$ e $1160{ }^{\circ} \mathrm{C}$, corroborando com os resultados da RL e AA. Estes resultados são atribuídos à formação de fases cristalinas à base de cálcio e/ou magnésio de elevada resistência mecânica a medida que se aumenta a temperatura de queima, como foi confirmado com a análise por DRX dos corpos de prova queimados que apresentaram a formação de anortita $\left(\mathrm{CaAl}_{2} \mathrm{Si}_{2} \mathrm{O}_{8}\right)$, diopsita $\left[\mathrm{Ca}(\mathrm{Mg}, \mathrm{Al})(\mathrm{Si}, \mathrm{Al})_{2} \mathrm{O}_{8}\right]$ e guelenita $\left[\mathrm{Ca}_{2} \mathrm{Al}(\mathrm{Al}, \mathrm{Si})_{2} \mathrm{O}_{7}\right]$. Por isso foi possível as 


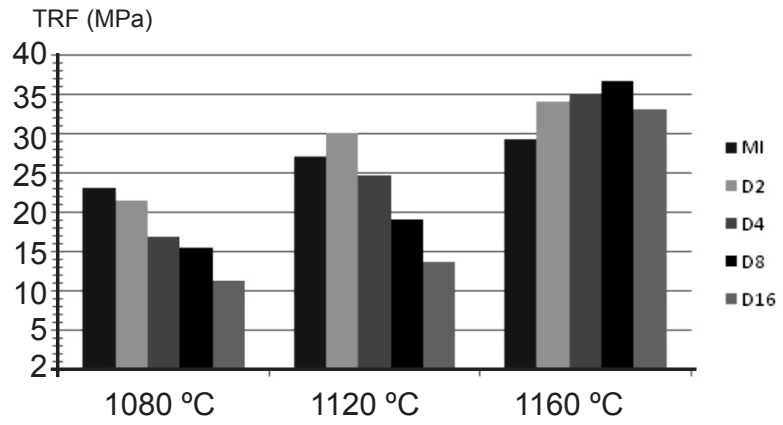

Figura 12: Resistência mecânica à flexão nas temperaturas estudadas.

[Figure 12: Flexural strength at the temperatures studied.]

formulações compostas com carbonato dolomítico obter resistência mecânica maior que a MI, mesmo apresentando maior porosidade que a massa de referência. Assim, o carbonato dolomítico se mostrou eficiente na melhoria da resistência mecânica da massa cerâmica.

A NBR 13818:1997 da ABNT [13] determina as características físicas que as placas cerâmicas obtidas pelo método de prensagem devem apresentar segundo a absorção de água e correspondente resistência mecânica. Comparando os resultados da AA e TRF obtidas na pesquisa com os parâmetros exigidos pela supracitada norma, pode-se observar que somente as formulações MI e D2 queimadas a $1080{ }^{\circ} \mathrm{C}$ atenderam as exigências das características físicas para o revestimento do tipo semiporoso, ou seja, AA variando de $6 \%$ a $10 \%$ e TRF maior ou igual a 18 MPa. A formulação D4 atendeu somente o requisito da AA. Em relação aos corpos de prova queimados a $1120^{\circ} \mathrm{C}$, observa-se que a formulação D2 atendeu as especificações para revestimento do tipo grês, $0,5 \%$ $<\mathrm{AA} \leq 3 \%$ e TRF $\geq 30 \mathrm{MPa}$, sendo que a formulação MI não atendeu a exigência mínima de resistência mecânica para este tipo de cerâmica de revestimento prensada. Isto mostra que um pequeno acréscimo do carbonato dolomita na massa promoveu uma melhoria significativa no produto final queimado a 1120 ${ }^{\circ} \mathrm{C}$. Já a formulação $\mathrm{D} 4$ atendeu aos parâmetros da norma para revestimento do tipo semigrês ( $3 \%<\mathrm{AA} \leq 6 \%$ e TRF $\geq 22)$ e a formulação D8 aos parâmetros do revestimento semiporoso. A $1160{ }^{\circ} \mathrm{C}$, todas as composições com dolomita apresentaram as características físicas de AA e resistência mecânica dentro dos parâmetros exigidos para o revestimento do tipo grês. A massa básica industrial obteve somente a AA compatível para este tipo de revestimento. Desta forma, fica mais uma vez evidenciado a eficiência do efeito da dolomita combinada ao tipo de massa industrial estudada em promover uma melhoria significativa nas propriedades mecânicas dos corpos cerâmicos queimados na temperatura mais elevada, devido a formação mais acentuada de fases cristalinas à base de cálcio e magnésio conferidos nestes corpos de prova, mesmo apresentado maior porosidade como foi observado com a formulação D16, por exemplo.

A micrografia da superfície de fratura da MI queimada a $1120{ }^{\circ} \mathrm{C}$ apresentada na Fig. 13 mostra uma topografia característica de um corpo cerâmico com bom nível de sinterização, ou seja, uma estrutura lisa e vitrificada,

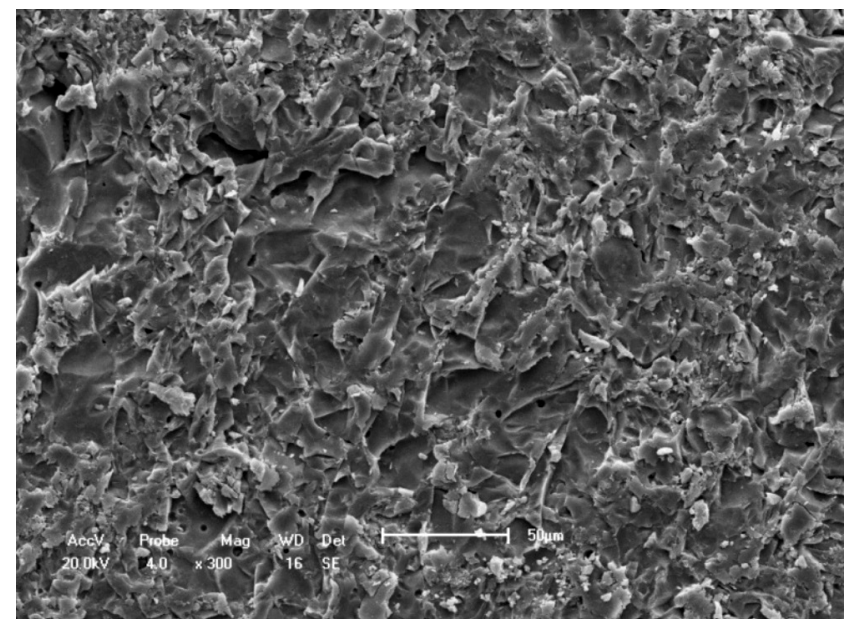

Figura 13: Micrografia obtida por microscopia eletrônica de varredura da $\mathrm{MI}$ queimada a $1120^{\circ} \mathrm{C}$.

[Figure 13: SEM micrograph of IM sample fired at $1120^{\circ} \mathrm{C}$.]

apresentando alguns poros isolados e de forma esférica que caracterizam a fase final de sinterização. Estes poros são decorrentes do aprisionamento dos gases liberados como a da hematita, a fase vítrea envolve todos os poros e os gases neles contidos não podem sair, o que evidencia também a redução da retração dos corpos de prova da MI queimados na maior temperatura.

De acordo com micrografia obtida por MEV da composição D16 queimada a $1120{ }^{\circ} \mathrm{C}$ (Fig. 14), observa-se que a microestrutura apresenta uma topografia mais grosseira e rugosa, maior quantidade de poros com maior tamanho e de formas irregulares. Isto é resultado principalmente da decomposição e saída do $\mathrm{CO}_{2}$ e das reações dos óxidos alcalinos terrosos com os demais componentes da massa que tendem a formar novas fases cristalinas e inibe a formação de fase vítrea. Esta análise também corrobora com os resultados obtidos por DRX das amostras queimadas com maior teor de dolomita na massa, onde se verificou uma maior formação de fases cristalinas à base de cálcio e magnésio.

Os resultados da análise química por espectroscopia de

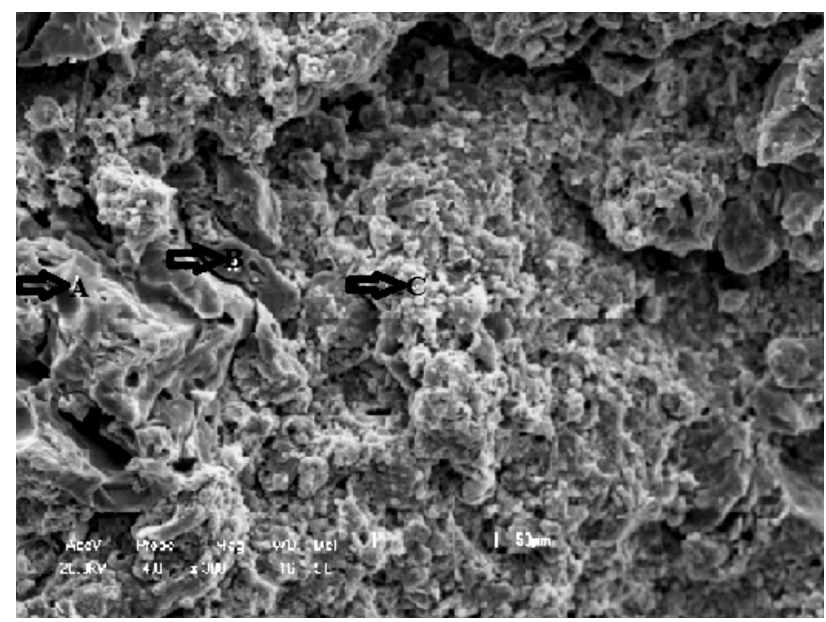

Figura 14: Micrografia obtida por microscopia eletrônica de varredura da formulação D16 queimada a $1120^{\circ} \mathrm{C}$.

[Figure 14: SEM micrograph of D16 sample fired at $1120^{\circ} \mathrm{C}$.] 
energia dispersiva (EDS) feita nos pontos A, B e C mostraram que a região do ponto A é predominantemente rico em silício e na região do ponto $\mathrm{B}$ é composta majoritariamente por silício, alumínio, potássio e ferro. Enquanto isso, a região do ponto $\mathrm{C}$ há uma grande concentração de magnésio e cálcio, além de silício e alumínio. Também se pode observar na micrografia ampliada do ponto C (Fig. 15) que há a formação de cristais que podem estar associados às fases cristalinas à base de cálcio e magnésio identificados no DRX de queima da formulação D16. Assim fica mais evidente que a presença dos carbonatos na massa industrial alterou o curso das reações e transformações durante a queima, proporcionando a formação de novas fases e dificultando a uma maior formação de fase vítrea e que, desta forma, alteraram as propriedades tecnológicas do produto final, como foi verificado nos ensaios físicos-mecânicos dos corpos de prova.

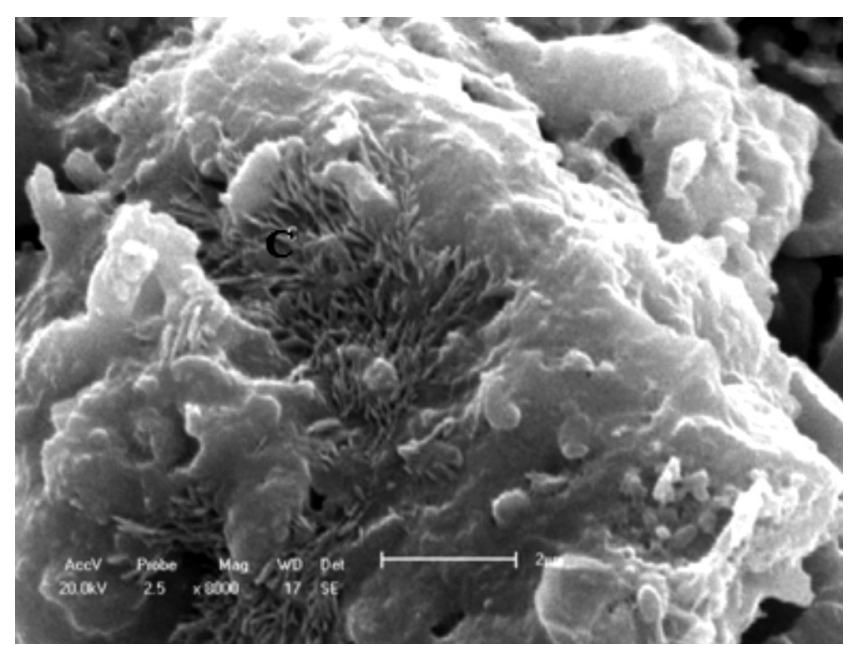

Figura 15: Micrografia obtida por microscopia eletrônica de varredura ampliada $8000 \mathrm{x}$ da região do ponto $\mathrm{C}$.

[Figure 15: SEM micrograph of point C from Fig. 14.]

\section{CONCLUSÕES}

A dolomita proporcionou mudanças e melhorias significativas na massa de referência, possibilitando o seu uso em escala industrial e desta forma, viu-se que: a presença da dolomita na massa industrial proporcionou uma melhor estabilidade dimensional na peça cerâmica com a redução da retração linear de queima com o aumento da concentração da dolomita na massa cerâmica; também se mostrou eficiente no aumento da resistência mecânica dos corpos cerâmicos, principalmente na temperatura mais elevada de queima. A composição com $2 \%$ de teor de dolomita superou os valores da massa de referência a partir da queima a $1120{ }^{\circ} \mathrm{C}$ e as demais formulações a $1160^{\circ} \mathrm{C}$. Tudo isto se deve a formação de fases cristalinas a base dos álcalis terrosos presentes nos carbonatos, fases estas que, mesmo diminuindo a densificação dos corpos cerâmicos, aumentam a sua resistência mecânica; a formulação com concentração de $2 \%$ de dolomita atendeu, segundo a NBR 13818:1997 da ABNT, as especificações de absorção de água e resistência mecânica para revestimento prensado do tipo semiporoso na queima a $1080{ }^{\circ} \mathrm{C}$ e do tipo grês a partir de $1120{ }^{\circ} \mathrm{C}$. Também a $1120{ }^{\circ} \mathrm{C}$, a composição com $4 \%$ de dolomita atendeu aos parâmetros da norma para revestimento do tipo semigrês e a formulação com $8 \%$ ao do tipo semiporoso. Na temperatura mais elevada de queima estudada, $1160{ }^{\circ} \mathrm{C}$, todas as formulações com dolomita, ou seja, com $2 \%, 4 \%, 8 \%$ e $16 \%$ presente na massa cerâmica, obtiveram seus resultados dentro dos parâmetros especificados pela norma para o revestimento do tipo grês; a dolomita piauiense mostrou-se viável como matéria-prima para aplicações em massa de cerâmica de revestimento.

\section{REFERÊNCIAS}

[1] CEPRO - Fundação Centro de Pesquisas Econômicas e Sociais do Piauí, "Diagnóstico e diretrizes para o setor mineral do estado do Piauí", Teresina, PI, Fundação CEPRO (2009).

[2] R. A. L. Soares, R. J. S. Castro, R. M. Nascimento, "Estudo da potencialidade da aplicação de uma argila contaminada com calcário na produção de placas cerâmicas", Cerâmica 58 (2012) 475-480.

[3] L. F. B. Marino, A. O. Boschi, "A Expansão Térmica de Materiais Cerâmicos. Parte IV: Efeitos da Adição de Dolomita", Ceram. Ind. 5, 1 (2000) 43-47.

[4] F. G. Melchiades, L. L. Silva, E. Quinteiro, A. P. F. Albers, J. B. Baldo, A. O. Boschi, “Alternativas para eliminar (ou reduzir) os furos no esmalte causados por partículas de calcário em revestimentos fabricados por via seca", Ceram. Ind. 6, 1 (2001) 7.

[5] L. F. B. Marino, A. O. Boschi, "A Expansão Térmica de Materiais Cerâmicos. Parte III: Efeitos da Adição de Calcita”, Ceram. Ind. 3, 4-6 (1998) 18-23.

[6] M. L. Varela, R. M. do Nascimento, A. E. Martinelli, D. Hotza, D. M. A. Melo, M. A. F. Melo, "Optimization of rational mineralogical analysis of ceramic", Cerâmica 51, 320 (2005) 387-391.

[7] P. W. Atkins, Físico química - Fundamentos, S. Paulo, Ed. LTC (2003).

[8] W. A. Deer, R. A. Howie, J. Zussman, "An introduction to the rock - Forming Mineral”, Logman Group Ltd., London, UK (1995) 340-355.

[9] M. Wesolowski, "Thermal decomposition of talc: A review", Thermochim. Acta 78 (1984) 395-421.

[10] J. C. P. Cestari, J. Vicenzi, C. P. Bergmann, "Utilização de resíduos de baixa granulometria como matéria-prima na produção de cerâmica vermelha: considerações quanto aos mecanismos de sinterização", Ceram. Ind. 12, 3 (2007) 27.

[11] C.M.F. Vieira,S. N. Monteiro, "Influência da temperatura de queima na microestrutura de argilas de Campos Goytacazes - RJ”, Cerâmica 49, 309 (2003) 6-10.

[12] F. G. Melchiades, A. O. Boschi, "A calcimetria como ferramenta para o controle de "bitola" em massas de revestimentos cerâmicos fabricados por via seca", Ceram. Ind. 11, 1 (2006) 7.

[13] Associação Brasileira de Normas Técnicas - ABNT, NBR 13818, "Placas cerâmicas para revestimento - Especificação e métodos de ensaios", Rio de Janeiro, RJ (1997).

(Rec. 19/06/2014, Rev. 14/09/2014, Ac. 19/09/2014) 